\title{
Local-level challenges to implementing health education programs in rural settings: a qualitative study
}

\author{
YOUSEF HAMIDZADEH ${ }^{1, A-c, E, F}$, MINA HASHEMIPARAST ${ }^{2, c-E}$, HADI HASSANKHANI $^{3, A, ~ B, ~ c, ~ D, ~}$ \\ HAMID ALLAHVERDIPOUR ${ }^{4,5, A-G}$ \\ ORCID ID: 0000-0003-3700-6185
}

${ }^{1}$ Candidate in Health Education, Department of Health Education and Promotion, Faculty of Health, Tabriz University of Medical Sciences, Tabriz, Iran

${ }^{2}$ Department of Public Health, Faculty of Health, Maragheh University of Medical Sciences, Maragheh, Iran

${ }^{3}$ Qualitative Research Center, Tabriz University of Medical Sciences, Tabriz, Iran

${ }^{4}$ Research Center of Psychiatry and Behavioral Sciences, Tabriz University of Medical Sciences, Tabriz, Iran

${ }^{5}$ Department of Health Education and Promotion, Faculty of Health, Tabriz University of Medical Sciences, Tabriz, Iran

A - Study Design, B - Data Collection, C - Statistical Analysis, D - Data Interpretation, E - Manuscript Preparation, F - Literature Search, G - Funds Collection

Summary Background. Health education is one of the main cores of primary health care (PHC). However, there is limited evidence on the difficulties of implementing health education programs. This study explored the barriers of implementing health education programs in Iranian rural communities.

Objectives. A qualitative study with conventional content analysis approach was conducted. Applying purposeful sampling, 34 rural folks and health care providers were employed to participate in the study. Data were collected through individually, semi-structured interviews. Data analysis continued until data saturation, when no new theme or idea emerged.

Material and methods. A qualitative study with conventional content analysis approach was conducted. Applying purposeful sampling, 34 rural folks and health care providers were employed to participate in the study. Data were collected through individually, semi-structured interviews. Data analysis continued until data saturation, when no new theme or idea emerged.

Results. Four themes, including "Ineffective teaching and learning processes", "Lack of health educators' motivation", "Communication gaps", and "Lack of resources and facilities for teaching and learning" emerged as the barriers of implementing health education programs in rural communities.

Conclusions. Several executive and communicational problems were identified as the local-level obstacles of implementing health education programs in rural areas. Better understanding on the extensive range of health education barriers in rural areas may be helpful for rural health workers and stakeholders in designing and/or revisiting health education programs in rural communities. Key words: health education, primary health care, programs, rural health, rural population.

Hamidzadeh Y, Hashemiparast M, Hassankhani H, Allahverdipour H. Local-level challenges to implementing health education programs in rural settings: a qualitative study. Fam Med Prim Care Rev 2019; 21(1): 30-34, doi: https://doi.org/10.5114/fmpcr.2019.82976.

\section{Background}

In many countries, the health status of rural populations is generally poorer than that of urban-living populations [1]. The situation may be more problematic for rural people living in remote and hard-to-reach settings. Evidence shows lower levels of health indicators in rural areas, compared to urban areas, particularly in developing countries [2]. Such disparities may emerge from poor socio-economic and environmental conditions, poor access to healthy nutrition, high exposure to health risk factors, and poor access to health care services in rural areas [3].

In the rural communities of developing countries, people have also less accessibility to media and the resources of informative materials. In order to provide them with health information and health literacy, there is a need for implementing health education programs offered by qualified heath care providers [4]. Effective health education programs may be helpful in promoting health status and health literacy, and alleviating the costs of health system services in rural communities $[5,6]$.

In Iran, as a developing country, the Governmental Primary Health Care (PHC) system was developed by the Ministry of
Health to provide the Iranian rural population with a better level of health care services. In this PHC system, rural health workers (RHWs) are the most vital health service delivery agents [22]. RHWs, who are working at the rural health houses, are also responsible for educating rural people on national and local health programs. If needed, the physicians, midwives, and health care professionals may inform and educate the rural people during weekly visits to the health houses [7]. Every rural health house in Iran is staffed by one or two RHWs. The activities of RHWs are supervised by the health professionals of rural health centers. The rural health centers include one main health center in the largest village and 4-6 health houses at the marginal villages. In these health centers, one or two physicians, depending on the population coverage, and a number of healthcare providers (including midwives, nurses, and family and environmental health technicians) provide the rural population with PHC services [8].

According to previous studies, the execution of health education programs in rural settings encounters some challenges and ambiguous hurdles $[9,10]$. It is also indicated that neither enough health education efforts in rural communities are conducted, nor enough knowledge on the barriers and challenges of health education programs in such areas is provided $[11,12]$. 
Previous evaluation of health education programs has indicated no distinct plan to overcome the obstacles of performing health education programs in rural areas $[13,14]$. Therefore, a thorough understanding on the challenges of implementing health education programs in rural contexts can contribute to effective planning and implementation of such programs.

\section{Objectives}

The aim of this study was to explore the barriers to implementing health education programs in Iranian rural communities.

\section{Materials and methods}

\section{Study design and participants}

A qualitative study using conventional content analysis approach was used to describe the challenges of implementing health education programs in Iranian rural communities. The participants were selected from the health services providers at the Ardabil health centers and the rural clients who were receiving health services from rural health houses during the study. Purposeful sampling method with maximum variation (in terms of age, gender, marital status, level of education and work experience) was used to recruit the participants.

Thirty-four participants, including nine rural clients and twenty-five health services providers participated in the study. Inclusion criteria were being of 18 years of age and older, using healthcare services, having more than one year of work experience as rural health worker, and willingness to participate in the study. More details about the participants are presented in Table 1.

\begin{tabular}{|c|c|c|}
\hline Variable & Frequency & Number (\%) \\
\hline \multirow{4}{*}{$\begin{array}{l}\text { Age } \\
\text { Mean = } 37.42\end{array}$} & $<30$ & $5(14 \%)$ \\
\hline & $30-40$ & $19(58 \%)$ \\
\hline & $40-50$ & 6 (17\%) \\
\hline & $>50$ & $4(11 \%)$ \\
\hline \multirow[t]{2}{*}{ Sex } & female & $26(76 \%)$ \\
\hline & male & $8(24 \%)$ \\
\hline \multirow{3}{*}{ Education } & $<$ diploma & $6(18 \%)$ \\
\hline & diploma & $11(32 \%)$ \\
\hline & > diploma & $17(50 \%)$ \\
\hline \multirow{7}{*}{ Job } & housewife & $9(26 / 5 \%)$ \\
\hline & health worker & 7 (20/5\%) \\
\hline & midwife & 5 (14/5\%) \\
\hline & doctor & 5 (14/5\%) \\
\hline & health supervisor & $3(9 \%)$ \\
\hline & health manager & $2(6 \%)$ \\
\hline & dehyar & $3(9 \%)$ \\
\hline \multirow{2}{*}{$\begin{array}{l}\text { Job history } \\
\text { Mean }=14.23 \text { years }\end{array}$} & $<15$ & $18(53 \%)$ \\
\hline & $>15$ & $16(47 \%)$ \\
\hline \multirow{2}{*}{$\begin{array}{l}\text { Nativity status from } 25 \\
\text { people providers }\end{array}$} & native & $14(56 \%)$ \\
\hline & non native & $11(44 \%)$ \\
\hline
\end{tabular}

\section{Data collection}

Data were collected through individually semi-structured interviews, which were performed using an interview guide. Each interview began with the following open-ended questions: "How would you describe health education programs in your village?", "How would you explain the clients' tendency towards health education programs in the rural settings?", and "What factors facilitate or inhibit the implementation of health education programs among rural folks?". Additionally, complementary probing questions such as "Would you please elaborate your explanation?" and "could you please tell me more about that?" were used to probe the participants' responses.

The time and place of the interviews were set based on the locales convenient to the participants. The interviews were often performed at the work places or homes of the participants. Each participant was interviewed once, for about 20-60 minutes. All the interviews were recorded using a voice recorder.

\section{Data analysis}

To analyze the data, all interviews were transcribed verbatim and the interviews were read and reread several times. The analysis was started by identifying the units of meaning that were extracted from the statements. The codes were generated, inductively, and the extracted codes were identified as categories based on the differences and similarities. Data analysis continued until data saturation in a way that no new theme or idea emerged [15]. MAXQDA v. 10 software was used to manage the textual data.

\section{Data trustworthiness}

Prolonged engagement with the interviewees, particularly the rural folks, helped the researchers in establishing trust and better understanding of the participants. The research team also assessed the interview data and findings at the each step of study process. Preliminary findings from the earlier interviews, interpretations and conclusions were tested by the participants (member check).

\section{Ethical considerations}

The ethics committee of Tabriz University of Medical Sciences (TBZMED) approved the study protocol (Ethics Code: IR.TBZMED.REC.1395.285). The aim and process of the study were explained to the participants and written informed consent was obtained. The interviews were recorded anonymously using code number.

\section{Results}

"This study explored the challenges of implementing health education programs in Iranian rural communities. Four main categories were described as the main challenges: "Ineffective teaching and learning processes", "Lack of motivation among health educators", "Communication gaps", and "Lack of resources and facilities for teaching and learning". These categories are presented as follow:

\section{Ineffective teaching and learning processes}

This concept reveals the issue of cognitive challenge in the learning process of the rural people and also the lack of qualified teaching skills among the health educators. This category was illuminated through two subcategories as follows:

\section{Learning problems}

Understanding was identified as a great challenge for a majority of the rural people who received health education programs. They faced many cognitive challenges ranging from understanding the new concepts about health recommendations, to practicing the aspects of health literacy. Hence, the lack of perception in some cases may have led the rural folks to poor acceptance of health education programs. Some of the participants pointed out to the poor learning talent of rural people in their statements: 
'The villagers won't learn anything even if you tell them 10 times, because their perception and talent are low. So, the health education programs in rural settings are never effective'.

Learning problems may be due to the illiteracy or low level of literacy among the rural population, which may have affected the efficiency of the programs. According to the participants, the literate and educated people learn better the healthy messages compared to the illiterate or less educated individuals in rural settings.

"Our problem is the illiterate and less educated people. We don't know how to teach them. Because, they do not perceive and learn very well".

\section{Lack of knowledge and teaching skills among RHWs}

As the participants believed, another barrier to effective teaching and learning process was the inadequate level of teaching skills among the health educators. It seems that a majority of health educators in rural settings adopt wrong approaches in delivering their knowledge. Poor delivery by lecturers without a clear understanding on the topics caused the rural folks to not comprehend the subjects of programs.

Based on the participants' beliefs, some of the health educators in rural settings are ineffective persons who are not knowledgeable about the contents of the programs, and do not communicate well. The health educators believed that the program by itself is a good idea, but they need to be taught more about the various topics of healthy issues and to be updated to acquire enough capability for effective implementing of health education programs:

"My capability is little and my knowledge isn't very modern and up-to-date. You know, I must be knowledgeable to transfer what I know".

\section{Lack of motivation among health educators}

This concept emphasized the role of the health educators' motivation to implement health education programs. The health educators reported some client-related factors as the key barriers for their motivation in implementing health education programs. According to the participants, the rural folks' lack of interest in learning was a reason for their low motivation to engage in the health education programs.

As participants noted, some clients do not like to spend time with the RHWs, and they just want to take the health services and run away. They do not want to listen to the health care professionals' recommendations. The rural clients were also not so motivated to query for the health information they need:

“... People don't appreciate the value of education and don't care about their health. They don't eager to learn and become more aware; they don't feel necessity for and interest in education".

The health educators also reported that some clients do not appreciate their efforts in education programs; they, thus, become less motivated to be enrolled in the health education programs. The lack of organizational support was another factor that the RHWs mentioned as their unwillingness to engage in the health education programs:

"... If I find a case of tuberculosis, I would be awarded ten dollars. Although our first responsibility is teaching, a good educator is not encouraged".

\section{Communication gaps}

Another barrier to effective implementation of health education programs in the rural settings was communication gaps between the villagers and the RHWs, as health educators. According to the participants, there were numerous reasons for these communication gaps, including the lack of receptivity and trust, and the interpersonal communication challenges.

\section{Lack of trust in the health educators' competencies}

This subcategory indicates distrust and inappropriate attitude of rural folks toward the RHWs, as health educators. Most of the participants believed that the rural folks pay less attention to the RHWs' educational programs and prefer to only take the general physicians' messages. They do not trust in the RHWs' competencies, and believed that the RHWs were less effective than the general physicians in increasing the knowledge of villagers about health issues. For instance, one of the villagers stated:

"The contents noted by them (the rural health workers) are old and out-of-date; but I think the physicians are better, because they are expert and their educational contents are based on the scientific contents".

\section{Interpersonal communication challenges}

According to the participants, accepting the health education programs was depended on the respectful communication of the RHWs. Inappropriate behavior of the RHWs, as the health educators, has made difficulties in the interpersonal communication. Consequently, the health education programs have less success in improving the health status of people in rural communities.

\section{Lack of resources and facilities for teaching and le- arning}

Lack of manpower, educational settings, tools and facilities, as well as financial resources were other barriers to successful implementation of the health education programs. A majority of participants emphasized the impacts of manpower on the provision of effective health education programs. In other words, not having enough time to perform the health education programs may have limited the opportunity of RHWs to implement health education programs, effectively.

"Our personnel are few, and we are too busy. We have covered all the health services from pre-natal to elderly healthcare services. So, we can't engage in health education programs".

In addition, the villagers pointed out to the lack of appropriate educational settings and equipment in the health houses:

"... The capacity of the education room is low, the location of education is too small and there is not enough chairs for the audiences to sit down".

\section{Discussion}

The aim of this qualitative study was to explore how the RHWs and the rural clients explain the barriers of implementing health education programs. According to our findings, one of the obstacles in rural health education was "ineffective learning and teaching processes". This category emphasized the insufficient ability of villagers in learning new concepts or information, and also the low skills of RHWs in teaching and conveying the educational materials. Inefficient teaching and learning means that the RHWs and the clients may not have enough ability to conduct an effective teaching-learning process, which consequently results in an unbeneficial health education process.

The poor cognition of villagers about the value of health messages may be due to several factors including illiteracy or low literacy, excessive workload, and also their weakness in perceiving health information. Moreover, the villagers' perceptual apprehension about the benefits and the values of health messages may not be well shaped in their minds. Consistent with our findings, in Pender's Health Promotion Model there is an emphasis on the importance of cognitive-perceptive factors, like the definition of health, the perception of health and the perceived benefits of health in increasing the probability of one's involvement in health education programs $[16,17]$. 
Lack of motivation among the health educators was one of the emerged categories that may have decreased the effectiveness of health education programs. Both the RHWs and the clients reported low engagement in health education programs, due to the less motivation to carry out the health education programs and the few demand needed for health information, respectively. The role of the management system in motivating community health workers has been demonstrated in numerous previous studies $[18,19]$. The findings of a study conducted in the north of Vietnam among health workers indicated that the motivation of RHWs was influenced by both financial and non-financial incentives, and one of the main motivating factors for them was appreciation by managers, colleagues and the community [20]. As a result, understanding the determinants of motivation by the supervisors of RHWs may be helpful in overcoming the causes of low motivation.

Another barrier noted by the RHWs was poor performance of clients in the health educational activities, which may have resulted in negative effects on the motivation of RHWs. In fact, in some of the remote villages, there may be no serious demand for health information, and, hence, many people may hold less intent to seek for health information. In agreement with this finding, Rubio-Valera et al. reported the participants' attitude toward health workers as one of the discovered barriers for the lack of motivation at the individual level [12].

The communication gap was another category that explained the difficulties of effective implementation of health education programs. Various researchers have indicated that inefficient communication skills are deterrent for the efficiency of health care services [21]. Moreover, the lack of effective communication with rural clients may have contributed to concealment in the needs of rural people to acquire their needed information, and, consequently, have reduced the consumers' satisfaction level [22, 23].

This study indicated that in the poor performance of health care delivery system and the poor communicative skills of the RHWs, a communication gap may be constituted. This result is consistent to the findings of a study in the rural area of Australia [24]. The big socio-cultural gap between the rural people and the health care providers may be the reason for the fact that the rural people attend less often in the health education programs provided by the rural health houses and notice less seriously to the health messages.

Promoting the communicational skills of RHWs may be considered as a helpful strategy to decrease the communicative gaps, and, consequently, to promote the quality of health care delivery and health communication activities. Previous studies have also demonstrated that short-term teaching courses may improve the quality of communicative skills of RHWs $[23,25]$. Based on another study in Zambia, those health workers who received some forms of training in the preceding one year, had better performance in their work [26].

Insufficient resources and facilities for teaching and learning was another category emerged from the viewpoints of the participants. The concurrency of insufficient resources and facilities with poor motivation and negative attitude of RHWs towards heath education programs, as well as the lack of equipment may have boosted up the inefficacy of rural health education programs. The appropriate distribution of RHWs was emphasized in the Almaty declaration [27]. According to the findings of Chhea et al., the lack of professionals and the inappropriate distribution of manpower were the challenges of most countries which may affect the quality of health care services delivery [28]. Also, the managers' support and working with peers were considered as important strategies to promote the palliative cares [29].

In the current study, besides the limited manpower, the lack of educational equipment was another factor attributed to failure in effective implementation of health educational programs in the rural health houses. Several previous studies reported the limited access to educational equipment in health centers as an effective factor for limiting the quality of health care services [30]. As noted by Cristancho et al., a part of these issues may be solved by using elaborated educational strategies, proper targeting, and identifying the interests of the audiences [31].

Our findings have implications for developing sustainable strategies to promote the performance of RHWs in the developing countries. As health education is substantial for health promotion and disease prevention, the higher recognition and apprehension of the extensive range of the obstacles may play a considerable role in the health promotion of rural communities. Providing the necessary equipment supplies and planning effective interventions, as well as establishing necessary measures by stakeholders, policy-makers, and the managers of health systems are suggested. Also, manpower provision, promoting motivation among RHWs and the clients, as well as providing the needed equipment and effective communications seem to be vital in effective implementation of rural health education programs [32].

Finally, the limitations of the present study may include the small sample size, which is due to the qualitative design of the study. The purposive selection of the participants only from the selected villages of Arabil province, Iran, may have limited the representativeness of the sample and generalizability of the results. Also, we did not triangulate the results of our study with quantitative approaches.

\section{Conclusions}

Our findings showed several obstacles in effective implementation of health education programs in rural settings. There were executive and communicational problems in effective delivery of health education programs. The extracted main categories indicated that lack of learning and teaching processes and discrepancy, as well as insufficient resources maybe attributed to the unsuccessful activities of RHWs in improving the health knowledge of villagers. Moreover, motivating the villagers for seeking health information may need health education capacity building among the RHWs, as a prerequisite. Promoting the communicational skills of the RHWs is also suggested as a priority in such a capacity building programs.

Acknowledgements. This study was a part of a large project supported by Tabriz University of Medical Sciences. The research team wishes to thank all the participants.

Source of funding: This work was funded from the authors' own resources.

Conflicts of interest: The authors declare no conflicts of interest.

\section{References}

1. Sommanustweechai A, Putthasri W, New ML, et al. Community health worker in hard-to-reach rural areas of Myanmar: filling primary health care service gaps. Hum Resour Health 2016; 14(64), doi: 10.1186/s12960-016-0161-4.

2. Hempel S, Gibbons M, Ulloa JG, et al. Rural Healthcare Workforce: a systematic review. VA ESP Project. 2015 \#05-226. Washington (DC): Department of Veterans Affairs (US); 2015.

3. Glazebrook R, Harrison S. Obstacles and solutions to maintenance of advanced procedural skills for rural and remote medical practitioners in Australia. Rural Remote Health 2006; 6(4): 502. 
4. Douthit N, Kiv S, Dwolatzky T, et al. Exposing some important barriers to health care access in the rural USA. Public Health 2015; 129(6): 611-620.

5. Weinhold I, Gurtner S. Understanding shortages of sufficient health care in rural areas. Health Policy 2014; 118(2): 201-214.

6. Salehi Zalani G, Bayat M, Shokri A, et al. Affecting factors on the performance of community health workers in iran's rural areas: a review article. Iran J Public Health 2016; 45(11): 1399-1410.

7. Azizi F. The reform of medical education in Iran. Med Educ 1997; 31(3): 159-162.

8. Couper I. Rural primary health care in Iran. S Afr Fam Pract 2004; 46(5): 37-39.

9. Kulig JC, Williams AM. Health in rural Canada. Vancover Toronto: UBC Press; 2011.

10. Strasser R. Rural health around the world: challenges and solutions. Fam Pract 2003; 20(4): 457-463.

11. Saunders R. The role of training and performance-related education in retention of community-based behavioral health workers in northeast Florida: Capella University; 2009 [cited: 26.12.2016]. Availaible from URL: http://search.proquest.com/docview/305159982.

12. Rubio-Valera $M$, Pons-Vigués $M$, Martínez-Andrés $M$, et al. Barriers and facilitators for the implementation of primary prevention and health promotion activities in primary care: a synthesis through meta-ethnography. PLoS ONE 2014; 9(2): e89554, doi: 10.1371/ journal.pone.0089554.

13. Holloway I, Stephanie W. Qualitative research in nursing and healthcare. 3rd ed. New York: Wiley-Blackwell; 2010.

14. Mayring P. Qualitative content analysis: theoretical foundation, basic procedures and software solution. Klagenfurt; 2014. Available from URL: https://www.ssoar.info/ssoar/handle/document/39517.

15. Graneheim UH, Lundman B. Qualitative content analysis in nursing research: concepts, procedures and measures to achieve trustworthiness. Nurse Educ Today 2004; 24(2): 105-112.

16. Peerson A, Saunders M. Health literacy revisited: what do we mean and why does it matter? Health Promo Int 2009; 24(3): 285-296.

17. Ouma WA, Thiong'o F, Ouma J, et al. Clients' perception of health workers and impact on health services offered at Kombewa demonstration health centre. Health Line 2004; 8(3): 42.

18. Akintola $\mathrm{O}$, Chikoko G. Factors influencing motivation and job satisfaction among supervisors of community health workers in marginalized communities in South Africa. Hum Resour Health 2016; 14(1): 54, doi: https://doi.org/10.1186/s12960-016-0151-6.

19. Ndima SD, Sidat M, Ormel H, et al. Supervision of community health workers in Mozambique: a qualitative study of factors influencing motivation and programme implementation. Hum Resour Health 2015; 13(1): 63, doi: 10.1186/s12960-015-0063-x.

20. Dieleman M, Cuong PV, Martineau T. Identifying factors for job motivation of rural health workers in North Viet Nam. Hum Resour Health 2003; 1(1): 10, doi: https://doi.org/10.1186/1478-4491-1-10.

21. Razee $H$, Whittaker M, Jayasuriya R, et al. Listening to the rural health workers in Papua New Guinea - the social factors that influence their motivation to work. Soc Sci Med 2012; 75(5): 828-835.

22. Barati M, Afsar A, Ahmadpanah M. Assessment of communication skills level among healthcare practitioners. Sci J Hamadan U Med Sci 2012; 19(1): 62-69.

23. Assefa F, Mosse A, Hailemichael Y. Assessment of clients' satisfaction with health service deliveries at Jimma University Specialized Hospital. Ethiop J Health Sci 2011; 21(2): 101-109.

24. Prout S, Lin I, Nattabi B, et al. 'I could never have learned this in a lecture': transformative learning in rural health education. Adv Health Sci Educ 2014; 19(2): 147-159.

25. Taghizadeh Z, Rezaiepour A, Mehran A, et al. Usage of communication skills by midwives and its relation to clients' satisfaction. $J$ Hayat 2007; 12(4): 47-55.

26. Mutale $\mathrm{W}$, Ayles $\mathrm{H}$, Bond $\mathrm{V}$, et al. Measuring health workers' motivation in rural health facilities: baseline results from three study districts in Zambia. Hum Resour Health 2013; 11(1): 8, doi: 10.1186/1478-4491-11-8.

27. Cumming M, Boreland F, Perkins D. Do rural primary health care nurses feel equipped for palliative care? Aust J Prim Health 2012; 18(4): 274-283.

28. Chhea C, Warren N, Manderson L. Health worker effectiveness and retention in rural Cambodia. Rural Remote Health 2010; 10(3): 1391.

29. Simbar M, Nahidi F, Dolatian M, et al. Assessment of quality of prenatal care in Shahid Beheshti Medical Science University centers. Int $J$ Health Care Qual Assur 2012; 25(3): 166-176.

30. Ghaffari Sardasht F, Jafarnejad F, Jahani N. Applying donabedian quality-of-care framework in assessing the structure of preconception care in urban health centers, Mashhad, 2012. J Mazandaran Univ Med Sci 2014; 24(116): 149-160. Available from URL: URL: http:// jmums.mazums.ac.ir/article-1-4279-fa.html.

31. Cristancho S, Garces DM, Peters KE, et al. Listening to rural Hispanic immigrants in the Midwest: a community-based participatory assessment of major barriers to health care access and use. Qual Health Res 2008; 18(5): 633-646.

32. Hamidzadeh $\mathrm{Y}$, Hashemiparast $\mathrm{M}$, Hassankhani $\mathrm{H}$, et al. Obstacles for Iranian rural population to participate in health education programmes: a qualitative study. Fam Med Com Health 2019; 7, doi: 10.1136/fmch-2018-000020.

Tables: 1

Figures: 0

References: 32

Received: 21.07.2018

Reviewed: 27.07 .2018

Accepted: 29.08.2018

Address for correspondence:

Prof. Hamid Allahverdipour

Department of Health Education and Promotion

Tabriz University of Medical Sciences

Golghasht Street

Tabriz, 14711

Iran

Tel./Fax: +98-41-33344731

E-mail: allahverdipourh@tbzmed.ac.ir 